\title{
Glaciological studies on Nelson Island, South Shetland Islands, Antarctica
}

\author{
Ren Jiawen, Qin Dahe, \\ Lanzhou Institute of Glaciology and Geocryology, Chinese Academy of Sciences, Lanzhou, Gansu 73000, China \\ J.R. Petit, \\ Laboratoire de Glaciologie el Géophysique de l'Environnement, 38402 Saint-Martin-d'Hères Cedex, France \\ J. JOUZEL, \\ Laboratoire de Modelisation du Climat et de l'Environnement, Division des Sciences de la Matière, CE Saclay, \\ 91191 Cedex Gif-sur-Yvette, France, and Laboratoire de Glaciologie el Géophysique de l'Environnement, \\ 38402 Saint-Martin-d'Hères Cedex, France \\ Wang Wenti, Liu Chen, Wang Xiaojun, \\ Lanzhou Institule of Glaciology and Geocryology, Chinese Academy of Sciences, Lanzhou, Gansu 73000, China \\ QIAN SONGLin, \\ Polar Research Instilute of China, Shanghai 200019, China \\ Wang XiaOXiang \\ Lanzhou Institute of Glaciology and Geocryology, Chinese Academy of Sciences, Lanzhou, Gansu 73000, China
}

\begin{abstract}
The ice cap on Nelson Island in the South Shetland Islands, West Antarctica, was studied between 1985 and 1989. The ice cap has an average thickness of $120 \mathrm{~m}$, it is temperate, exists under the sub-Antarctic maritime climate and almost completely covers the island. Owing to intense percolation of meltwater and, to some extent, liquid precipitation), the snow-firn layer is in the soaked facies, with a firn-ice transition at a depth of $25-26 \mathrm{~m}$ at the summit. A force-balance model suggests that the ice is almost linearly viscous but has a high viscosity. The model further suggests that basal sliding makes a larger contribution to the ice movement than does ice deformation. From 1970 to 1988 , the average accumulation rate was $120 \mathrm{~kg} \mathrm{~m}^{2} \mathrm{a}^{-1}$ at the centre, and between 1985 and 1989 the equilibrium-line elevation averaged $110 \mathrm{~m}$ a.s.l. Analysis of chemical impurities in the surface snow suggests that the precipitation source is mainly local marine air masses and that human activity has already exerted a detectable influence on the local environment.
\end{abstract}

\section{INTRODUGTION}

During the past few decades, Antarctic glaciological research has attracted widespread attention and has advanced rapidly with a series of important achievements (Robin and Swithinbank, 1987). This is because the physical characteristics and history of variations of the glaciers in Antarctica are not only of glaciological interest but are also relevant to problems of the global change of sea-level, of climate and of the environment. Since Antarctica is a vast area, there are noteworthy differences in the climate and in the basic features of the glaciers between different regions.

The South Shetland Islands, one of the areas which Antarctic explorers first visited, are located near the northernmost end of the Antarctic Peninsula. They consist of ten islands exceeding $100 \mathrm{~km}^{2}$ in area and a number of smaller islands (Fig. la). Under the sub-Antarctic maritime climate, glaciers on these islands are very different in physical characteristics from those at higher latitudes. From 1985 to 1989, the Chinese National Antarctic Research Expedition conducted scientific investigations on the ice cap of Nelson Island, an island in the middle of the South Shetland Islands (Fig. 1a). Basic glaciological data were obtained, including detailed maps of ice-surface and bedrock topography, ice thickness, stratigraphy in shallow pits and shallow cores, surface velocity and near-surface temperature, etc. In addition, chemical impurities in the surface snow and stable isotopes and the composition of an ash layer in ice cores were analysed. Although some of the results have been published individually Ren, 1988; Qian and Liu, 1989; Wang and 

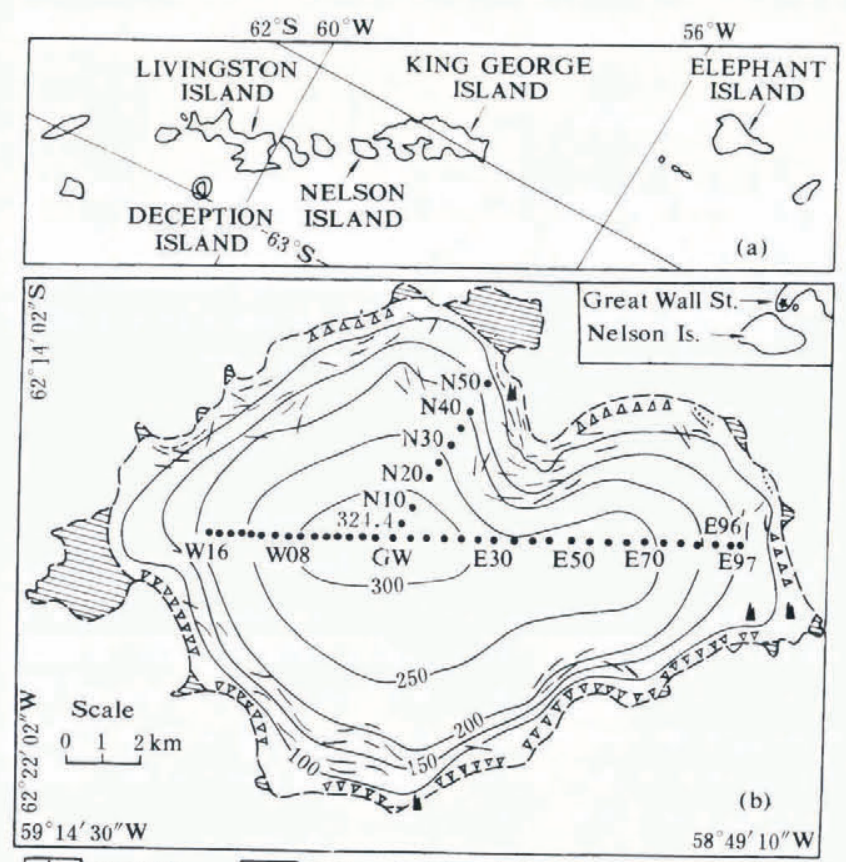

$59^{\circ} 14^{\prime} 30^{\prime \prime}$

$58^{\circ} 49^{\prime} 10^{\prime \prime} \mathrm{W}$

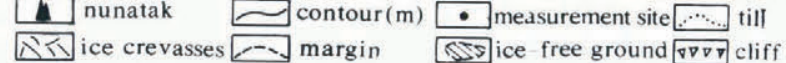

\section{Fig. 1. Maps of (a) the South Shetland Islands; and (b) the ice cap on Nelson Island showing the main measurement siles.}

others, 1990; Liu and others, 1991; Qin and others, 1993), it is useful to present a comprehensive discussion of the main results of this study.

\section{GEOMETRY OF THE NELSON ISLAND ICE CAP}

Nelson Island has an area of $164.8 \mathrm{~km}^{2}, 95 \%$ of which is covered by a permanent ice cap. The summit of the ice cap is $324.6 \mathrm{~m}$ a.s.l., and it reaches the ocean along a large part of its margin. The accumulation area occupies more than four-fifths of the total area. The equilibrium line, although varying somewhat with topography, had a mean elevation of about $110 \mathrm{~m}$ a.s.l. during the period of investigation.

Figure $1 \mathrm{~b}$ is a map of the ice cap showing the main measurement sites. Radio-echo sounding at 171 sites along two transects (north and east-west) vielded an average ice thickness of $120 \mathrm{~m}$ with a maximum of $169 \mathrm{~m}$ at E86. The radio-echo profiles also indicate that the bedrock undulates abruptly and irregularly (Fig. 2a). The surface slope increases toward the edge, particularly at about $4 \mathrm{~km}$ from the summit $(\mathrm{GW})$, where the slope changes rapidly from 0.05 at $3 \mathrm{~km}$ to 0.14 . The greatest change in bedrock slope is at about $3 \mathrm{~km}$.

\section{PHYSICAL CHARACTERISTICS OF THE NELSON ISLAND ICE GAP}

\subsection{Temperature}

The mean annual temperature was $-2.9^{\circ} \mathrm{C}$ at Bellingshausen Station between 1968 and 1983 (Jacka and others,

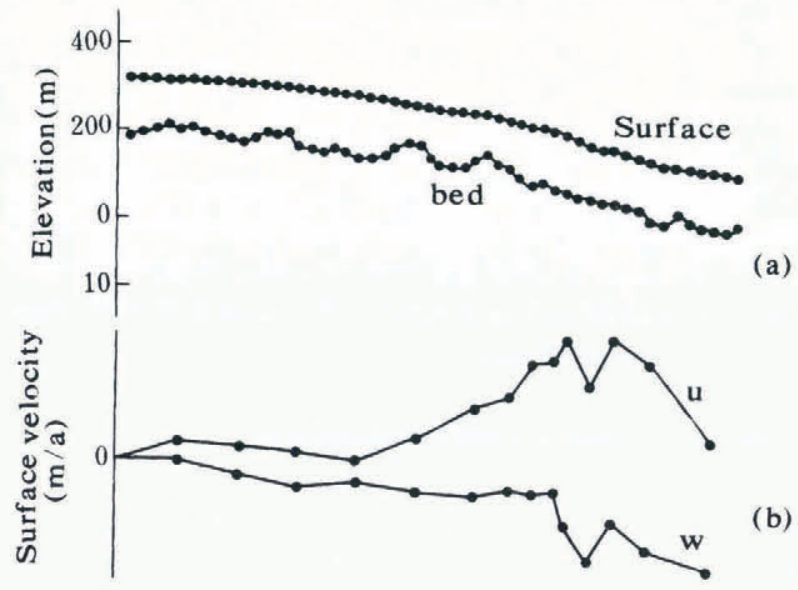

(a)
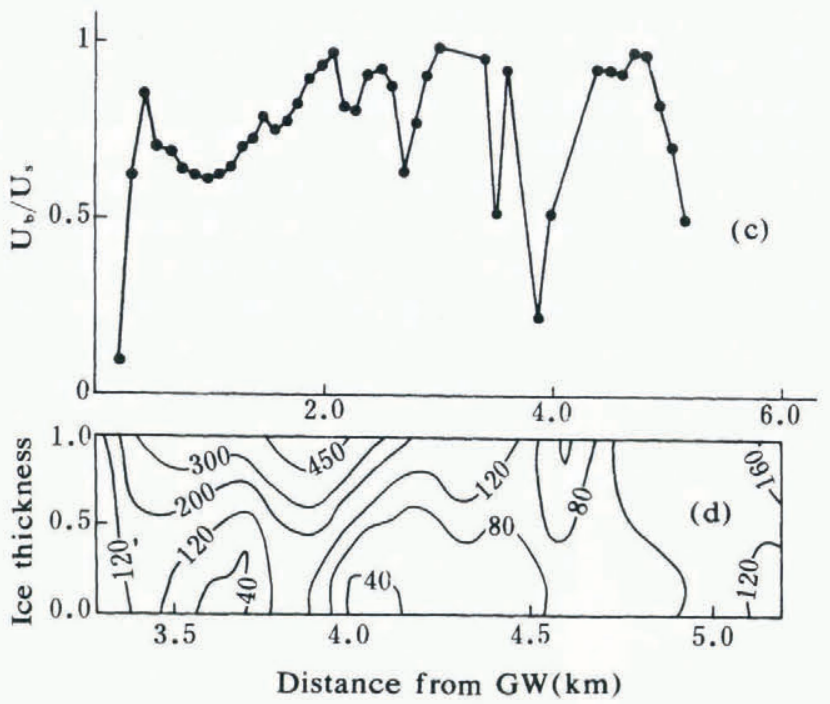

Fig. 2. Some features of the ice cap on. Velson Island along transect N. a. Ice-surface and bed elevations. b. Surfacevelocity components: $u$ is the horizontal component, positive toward the margin, and $w$ is the vertical component, positive upwards. $c$. Ratio of basal velocity $\left(u_{\mathrm{b}}\right)$ to surface velocity $\left(u_{\mathrm{s}}\right) . d$. Isolines of effective shear stress $\left(\tau_{\mathrm{e}}\right)$.

1984), and $-2.7^{\circ} \mathrm{C}$ at the Great Wall Station on King George Island between 1985 and 1988. From these and, assuming an adiabatic lapse rate between $0.7^{\circ}$ and $1.0^{\circ} \mathrm{C}$ $100 \mathrm{~m}$, it is estimated that the annual mean air temperature is between $-5^{\circ}$ and $-6^{\circ} \mathrm{C}$ at the summit of the Nelson Island ice cap. During the 1987-88 austral summer, a layer of water-saturated firn was encountered at a depth of $25-26 \mathrm{~m}$ in a $30 \mathrm{~m}$ core drilled at the summit GW). A similar layer was found at a depth of $15 \mathrm{~m}$ in a $20 \mathrm{~m}$ core obtained at site N30. The temperature measured immediately after drilling was $0^{\circ} \mathrm{C}$ at all depths in these boreholes. Stratigraphic profiles demonstrated that the water layer was at the base of the firn in both cases.

In the 198586 summer, three boreholes were drilled, especially for temperature measurements, by using a steam drill. The holes were at 90, 140 and $160 \mathrm{~m}$ a.s.l., and were $13,11.8$ and $12.5 \mathrm{~m}$ deep, respectively. The average temperature at $10 \mathrm{~m}$ depth was $-1.5^{\circ} \mathrm{C}$ at $90 \mathrm{~m}$, $0.7^{\circ} \mathrm{C}$ at $140 \mathrm{~m}$ and $-0.1^{\circ} \mathrm{C}$ at $160 \mathrm{~m}$ (Ren, 1990). Obviously, the temperature regime is controlled by the percolation of water from the surface, mainly from surface melting but also from liquid precipitation during the 
summer. Where the snow-firn layer is thicker, water penetrates deeper and the $10 \mathrm{~m}$ temperature is higher. Conversely, near the edge of the ice cap, where the snowfirn layer is thinner or absent, most water is lost by runoff. The temperature at depth is undoubtedly at the melting point. This temperature distribution is in striking contrast to that of cold glaciers in polar regions and of glaciers in middle or low latitudes, but is well known from glaciers in similar climates.

\subsection{Surface velocity and dynamics}

From January 1988 to February 1989, coordinates of 40 stakes, set along transects $\mathrm{N}$ and $\mathrm{E}$, were measured three times and the surface velocity at each site was calculated (Liu and others, 1991). The velocity increases toward the margin with a summer maximum of $20.6 \mathrm{ma}^{-1}$ and an annual maximum of $15.5 \mathrm{ma}^{-1}$ at $\mathrm{N} 50$. Figure $2 \mathrm{~b}$ illustrates the horizontal $(u)$ and the vertical $(w)$ components along transect $\mathrm{N}$. Both horizontal and vertical velocities increase sharply at about $4 \mathrm{~km}$ from GW. This is consistent with the change in surface slope mentioned above. Near the margin, the horizontal velocity decreases but the vertical velocity continues to increase (becomes more negative).

Many studies of the dynamics of large ice sheets have been reviewed by Paterson (1981). In previous studies, one of the basic assumptions is often that, on a large scale, the bedrock is horizontal. Locally, on an ice sheet or small ice cap, this assumption is invalid.

Van der Veen and Whillans' (1989) force-budget technique was used to develop a two-dimensional dynamic model along transect N. Using this method, forces acting on an ice mass are divided into the driving stress and the resisting stresses, and the velocity field is coupled to the stress field by a constitutive relation (iceflow law). Thus, an analysis of stresses within an ice mass can be undertaken only if the surface velocity and the geometry of the ice mass are known. Figure 2c illustrates the resulting computed ratio of basal $\left(U_{\mathrm{b}}\right)$ and surface velocities $\left(U_{s}\right)$. Except for a few sites, basal velocity is greater than $50 \%$ of the surface velocity, implying that most of the ice movement is by basal sliding.

Figure $2 \mathrm{~d}$ shows isolines of effective shear stress $\left(\tau_{\mathrm{e}}\right)$ in the section down-glacier from the $3 \mathrm{~km}$ (from GW) position. Between GW and the $3 \mathrm{~km}$ position, $\tau_{\mathrm{e}}$ varies very little and is less than $40 \mathrm{kPa}$. However, it changes significantly over a short distance near the $4 \mathrm{~km}$ position, reaching a maximum in excess of $400 \mathrm{kPa}$. Although this is the region of steepest surface slope, so large a value is questionable. Transect $\mathrm{N}$ does not coincide with a flow line, especially between $\mathrm{N} 30$ and N50, where there is a noticeable lateral velocity, but our two-dimensional model assumes the lateral velocity is zero. This certainly causes some error in the result.

In our calculation, the Glen-Nye flow law $\dot{\varepsilon}_{\mathrm{e}}=A \tau_{\mathrm{e}}{ }^{n}$ was used as the constitutive relation. Here, $\dot{\varepsilon}_{\mathrm{e}}$ is the effective strain rate, and $A$ and $n$ are constants. Substitution of the measured surface velocities in the model yields values of $n$ and $A$ of 1.1 and $5.01 \times 10^{5}$ $\mathrm{kPa}^{-1.1} \mathrm{a}^{-1}$, respectively. The low $n$ and high $A$ imply that the ice, although almost linear in its response to stress, has a rather high viscosity.

\section{STRATIGRAPHY AND ACCUMULATION RATE}

\subsection{Stratigraphy}

During the summers of 1985-86, 1987-88 and 1988-89, 54 shallow pits, up to $2 \mathrm{~m}$ deep were dug for measurement of stratigraphic profiles. Most pits were on transect $\mathrm{N}$ and in some cases pits were dug at the same site in two or more years. Unfortunately, the profiles do not show clear seasonal features sufficiently consistent to be useful.

Figure 3 shows stratigraphic, stable-isotope and density profiles from three cores drilled at N50, N30 and GW (from Qin and others, 1994). There are no noticeable seasonal variations in the isotope profiles; this is certainly a consequence of the intense percolation of surface water. The stratigraphic and density profiles indicate that the firn-ice transition is at a depth of 25 $26 \mathrm{~m}$ at GW and at about $15 \mathrm{~m}$ at N30. This is a little deeper than reported by Orheim and Govorukha (1982) on King George Island.

\subsection{Accumulation rate}

At most measurement sites, we have snow-accumulation data spanning at most 2 months. This is because of the loss of stakes during the winter. Data spanning one massbalance year (February 1988-February 1989) at N30, $\mathrm{N} 40$ and $\mathrm{N} 50$ yield accumulation rates of 790, 1050 and $110 \mathrm{~kg} \mathrm{~m}^{-2} \mathrm{a}^{-1}$, respectively. However, a clear ash layer was found in all three cores (Fig. 3). Element-composition analysis confirmed that all three ash layers are from the 1970 eruption of the Deception Island volcano (Qin and others, 1994). From this, we obtained average accumulation rates between 1970 and 1988 of $1200 \mathrm{~kg} \mathrm{~m}^{-2} \mathrm{a}^{-1}$ at GW, $700 \mathrm{~kg} \mathrm{~m}^{-2} \mathrm{a}^{-1}$ at $\mathrm{N} 30$ and $6 \mathrm{~kg} \mathrm{~m}^{-2} \mathrm{a}^{-1}$ at N50, or slightly less than indicated by the stake data. The relatively high accumulation at $\mathrm{N} 40$ (stake data) is a result of snowdrift in a location where the surface is somewhat concave. Three other $10-15 \mathrm{~m}$ cores were taken in the eastern part of the ice cap (at E30, E55 and E95) but no ash layer was found in them.

The equilibrium-line elevation was determined from pit and stake data to be $110 \mathrm{~m}$ a.s.l. between 1985 and 1989, with a relatively high value in 1985 86 and a low value in 1988-89. Several snow pits dug in the summer of 1985-86 show that the equilibrium-line elevation is about $150 \mathrm{~m}$ on King George Island (Ren, 1988). This is consistent with equilibrium-line elevations in the early 1970s reported by Orheim and Govorukha (1982). That the $10 \mathrm{~m}$ temperature at $150 \mathrm{ma}$.s.l. on King George Island is close to that of $90 \mathrm{~m}$ a.s.l. on the Nelson Island ice cap (Ren, 1990) also implies a higher elevation of the equilibrium line on King George Island.

\section{SOLUBLE IMPURITIES IN THE SURFACE SNOW}

At the summit of the Nelson Island ice cap, snow samples were collected at $0.1 \mathrm{~m}$ intervals from the surface to a depth of $2 \mathrm{~m}$ in a snow pit. Concentrations of soluble anions and cations in these samples were measured with an accuracy of ppb (Fig. 4) (Qin, 1991; Qin and others, 


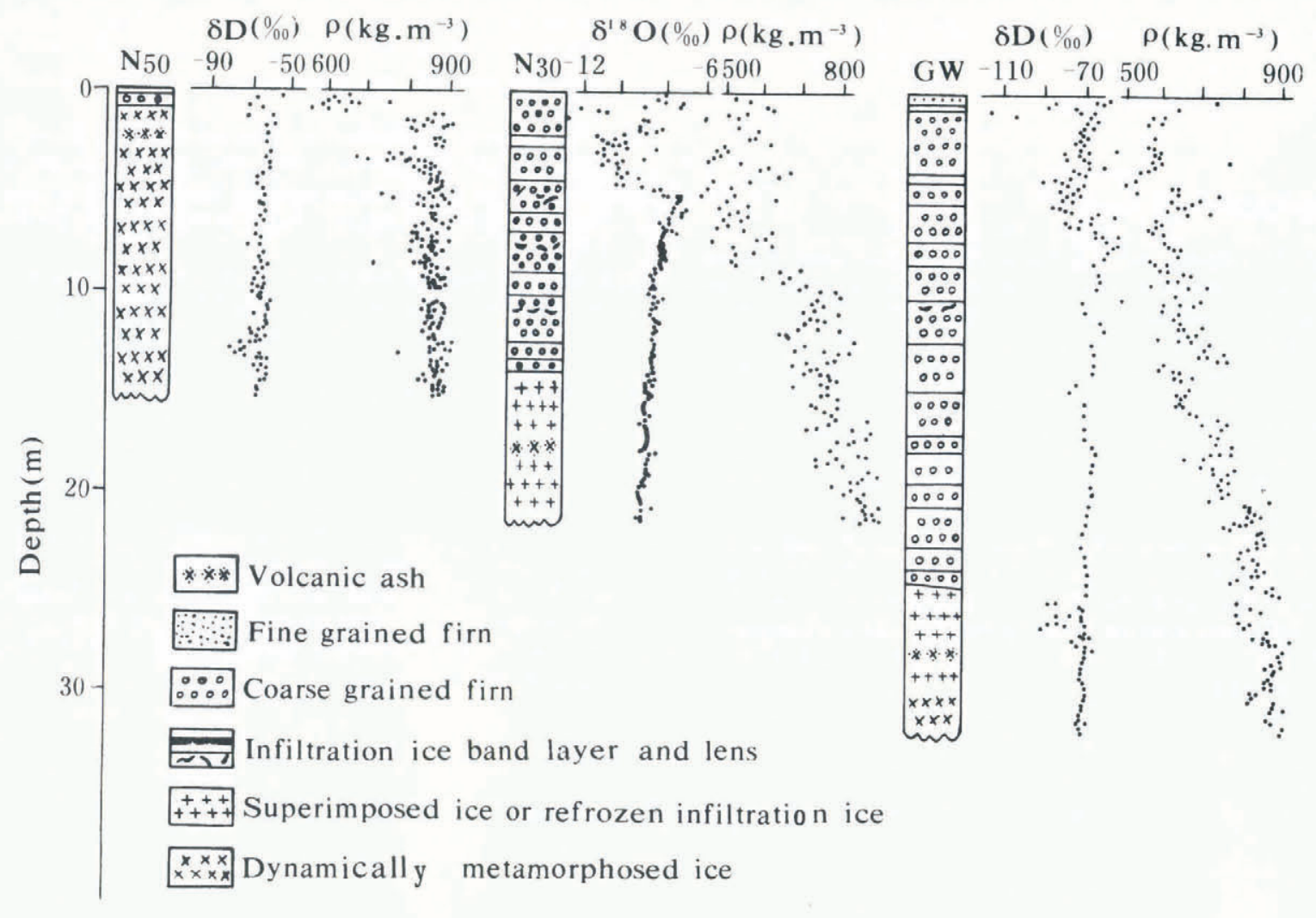

Fig. 3. Stratigraphic profiles of ice cores with stable-isotope and density profiles (from Qin and others, 1994).

1993). Unlike the stable-isotope profiles, the ionic concentrations all vary markedly with depth, implying that primary seasonal variations in impurities in the surface snow are not destroyed by percolating water. Figure 4 shows that ionic concentrations in the winter snow, in the lower part of the snow pit, are higher than in the summer snow, especially for ions from marine sources such as $\mathrm{Na}^{+}$and $\mathrm{Cl}$. Comparison of ionic concentrations and deposition rates at this site with five others in West Antarctica Qin and others, 1993) indicates that the concentration and particularly the deposition rate of all

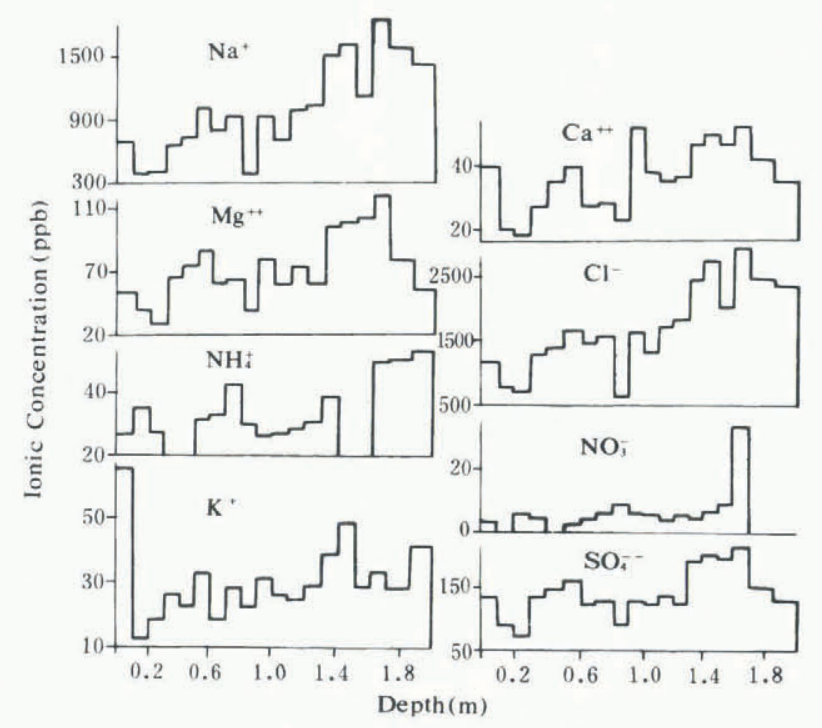

Fig. 4. Measured ionic concentrations in the surface snow at GW (from Qin, 1991). ions, except $\mathrm{NO}_{3}$, are highest on Nelson Island. For example, the deposition rate of $\mathrm{Na}^{+}, \mathrm{Cl}^{-}$and $\mathrm{NH}_{4}{ }^{+}$and $\mathrm{SO}_{4}{ }^{2}$ is $10-1000$ times higher than that at the South Pole. From this, it is concluded that, on Nelson Island, most precipitation is from local marine air masses and that nitrate distribution is basically determined by largescale atmospheric processes rather than by local factors.

\section{CONGLUDING REMARKS}

Nelson Island is in a sub-Antarctic region in the South Atlantic Ocean where temperature is high, precipitation is plentiful and local marine air masses are the major vapour source. The ice cap on Nelson Island is thin and temperate. In comparison with other nearby glaciers, such as the ice cap on King George Island, the firn layer is thicker, the temperature in the surface layer is higher at similar altitudes and the equilibrium-line elevation is lower on Nelson Island.

Force-balance modelling suggests that basal sliding makes a major contribution to the ice movement and that the viscosity is rather high, despite the high temperature and the abundance of water from intense surface melting and liquid precipitation.

\section{ACKNOWLEDGEMENTS}

This work is supported by the National Natural Science Foundation of China and the State Committee for Antarctic Research of China. We deeply appreciate the special help of the Second, Fourth and Fifth Chinese National Antarctic Research Expeditions in our field 
work. Special thanks are given to Professor R. LeB. Hooke and two other anonymous reviewers for their constructive comments on the manuscript.

\section{REFERENCES}

Jacka, T. H., L. Christou and B.J. Cook. 1984. A data bank of mean monthly and annual surface temperatures for Antarctica, the Southern Ocean and South Pacific Ocean. A.NARE Res, Notes 22.

Liu Chen, Qin Dahe, Wang Xiaojun and Qian Songlin. 1991. The surface flow of Nelson ice cap, West Antarctica. Antarct. Res., 3 4), 11-17. [In Chinese with English summary.]

Orheim, O. and L. S. Govorukha. 1982. Present-day glaciation in the South Shetland Islands. Ann. Glaciol., 3, 233- 238.

Paterson, W.S. B. 1981. The physics of glaciers. Second edition. Oxford, etc., Pergamon Press.

Qian Songlin and Liu Cheng, 1989. Measurement of ice thickness on the Velson ice sheet. In Guo Kun, ed. Proceedings of the International Symposium on Antartic Research. Beijing, China Ocean Press, 28-32.

Qin Dahe. 1991. Characteristics of stratigraphy and glaciochemistry on top of Nelson ice cap, Antarctica. Antarcl. Res., 3 (3), 1-7. [In Chinese with English summary.]
Qin Dahe, P. A. Mayewski, C. P. Wake and Yang Qinzhao. 1993. Anions and cations in a snow pit on the top of Nelson ice cap, South Shetland Islands, Antarctica. Chinese Science Bulletin, 38 4), 312-316.

Qin Dahe, G. A. Zielinski, M.S. Germain, Ren Jiawen, Wang Xiaoxiang and Wang Wenti. 1994. Use of tephrochronology in the evaluation of accumulation rates on Nelson Island ice cap, South Shetland Islands, Antarctica. Science in China, Ser. B, 37 10) 1272 1278.

Ren Jiawen. 1988. Development conditions and mass balance of the glaciers nearby the Great Wall Station, Antarctica. In A collection of Antarctic scientific explorations. 5. Beijing, Science Press, $247-255$.

Ren Jiawen. 1990. Temperature regime of the glaciers in the neighbourhood of Great Wall Station, Antarctica. Antart. Res, 2 2 , 22-27. [In Chinese with English summary.]

Robin, G.de Q. and C. Swithinbank. 1987. Fifty years of progress in understanding ice sheets. J. Glaciol., Special Issue, 33-47.

Van der Veen, C. J. and I. M. Whillans. 1989. Force budget: I. Theory and numerical methods. F. Glaciol., 35 119), 53-60.

Wang Xiaojun, Qin Dahe, Liu Chen and Qian Songlin. 1990. Stratigraphic studies of the snow and the process of the ice formation on Nelson ice cap, Antarctica. Antarcl. Res., 2 2), 13-21. [In Chinese with English summary.]

MS received 21 March 1994 and accepted in revised form 25 October 1994 